\title{
ELES-Model Based Housing Affordability Comparative Research of Urban Households in Beijing Between 2004 and 2014
}

\author{
Aihua $\mathrm{Li}^{1}$. Qingqing Mo ${ }^{1}$. Wenbin $\mathrm{Li}^{1}$. \\ Yuejin Zhang ${ }^{1}$
}

Received: 26 August 2015 / Revised: 15 September 2015 / Accepted: 16 September 2015 /

Published online: 24 September 2015

(C) Springer-Verlag Berlin Heidelberg 2015

\begin{abstract}
In this paper, we apply the model of the extended linear expenditure system to measure housing affordability of urban households in Beijing, and calculate the affordable housing areas of urban households which are on different income levels in Beijing in 2014 and 2004. In this study, we find that, the household disposable incomes of urban households in Beijing increase along with the development of economy, all income levels of urban households in Beijing can cover the expenditures of their basic life needs, and housing affordability of urban households of different income levels in Beijing is increasing as well. The increasing disposable incomes enhanced the housing affordability of urban households in Beijing from the year 2004 to the year 2014, and all income levels of urban households in Beijing have improved their housing conditions. However, from the view of the affordable housing squares, their housing conditions depend on the housing price closely. If the growth of house price is faster than the growth of housing affordability, the affordable housing squares will decrease, and the housing condition of urban households in Beijing will be worse from 2004 to 2014. And the comparison between 2013 and 2014 shows the housing affability problem has been relieved.
\end{abstract}

Aihua Li

neu_aihua@126.com

Qingqing Mo

moqingqing91@126.com

Wenbin Li

liwenbin@vip.sina.com

Yuejin Zhang

zhangyj8268@163.com

1 Central University of Finance and Economics, Xueyuan South Road 39, Haidian District, Beijing 100081, China 
Keywords Household disposable income - The expenditure of basic life need . The extended linear expenditure system $\cdot$ Housing affordability

\section{Introduction}

Housing is one of the basic necessities. For most people, house is not just a building, but a home like a warm haven that can give people a sense of security. China has a large population. Along with urbanization and population growth, a large number of people come into cities, which brings a lot of demands for housing. Besides, with income increasing, urban residents need to improve living conditions, which also brings housing demands. Although there is such a large demand for housing, not many urban residents can afford a house in big cities. However, there is a noticeable phenomenon in some cities in China, ghost towns, where have a high house vacancy rate in urban cities. This is very strange, one side is the high demands for houses, and another side is high house vacancy rate. Are the incomes of urban households too low or the house prices too high? Perhaps, there are other reasons that account for housing problem. Housing problem relates to the stability of society, it's meaningful for us to find out the reason why some urban households cannot afford a proper house in urban cities.

Foreign scholars and domestic scholars proposed a number of the concept of housing affordability [1-3]. After considering the various concepts of housing affordability, we define housing affordability as the ability to pay money when urban households get a house from real estate market [4]. There are many methods of studying housing affordability, such as price-income ratio [5, 6], housing affordability index [7-9], and so on. These methods have some advantages, such as easy to understand and calculate, but still have some disadvantages, like unable to measure housing affordability accurately, and so on .The model we use in this paper is the extended linear expenditure system (ELSE) [10]. The extended linear expenditure system is on the basis of the linear expenditure system [11]. There are extensive researches based on ELES in foreign and domestic [12-16], ELES is a more sophisticated model. Li [17] had used ELESmodel to calculate housing affordability of urban households in Beijing in 2004, and had proved the applicability of this model in the study of housing affordability. Li [18] had used this model to do comparative studies of the same city in different years. In this paper, we get the latest data of urban households in Beijing, measure and compare housing affordability of urban households on different income levels in Beijing in 2014 and 2004, and find out the changes of housing affordability in Beijing between 2004 and 2014, and make some comparisons between 2013 and 2014.

In this paper, our goal is to find out the reason for housing problem and come up with the solutions to housing problem. This article consists of four sections, the first section is introduction, and the second part is the model. Empirical Research and conclusion are in the third and the fourth section. We measure the housing purchasing power of urban residents in Beijing in 2014 and 2004 based on the extended linear expenditure system, analyze the changes of the housing affordability of urban residents in Beijing between 2004, 2013 and 2014. 


\section{Model}

Based on the linear expenditure system [11], Lluch C [10] took into account the savings and proposed the extended linear expenditure system model [17]. The expression of the extended linear expenditure system model is as follows:

$$
V_{i}=P_{i} r_{i}+\beta_{i}\left(Y-\sum_{i=1}^{n} P_{i} r_{i}\right)
$$

Here, $V_{i}$ is the annual expenditure of a household spending on goods or services of $i$-th. $V=\sum_{i=1}^{n} V_{i}, V$ is the total annual expenditure that the household spends on the total goods and services, $P_{i}$ is the price of goods or services of $i$-th. $r_{i}$ is the annual basic amount of goods or services of $i$-th in the household. $P_{i} r_{i}$ is the annual expenditure that the household spends on the basic amount of goods or services of $i$-th. $Y$ is the income of the household. $\beta_{i}$ is the marginal share of the budget of goods or services $i$-th, the proportion of income used on savings is $\beta_{n+1} \cdot \sum_{i=1}^{n} \beta_{i}<1$, and $\sum_{i=1}^{n+1} \beta_{i}=1$.

Let

$$
P_{i} r_{i}-\beta_{i} \sum_{i=1}^{n} P_{i} r_{i}=b_{i}
$$

Then, the expression of the extended linear expenditure model is as follow:

$$
V_{i}=b_{i}+\beta_{i} Y
$$

First, we use the cross-sectional data to run a regression, then we can get the estimated values of $b_{i}$ and $\beta_{i}$. Second, we calculate the annual expenditure that the household spends on the basic need of each consumer item and the total annual expenditure that the household spends on the total basic needs. Finally we estimate housing affordability of the household.

According to Beijing Statistical Yearbook 2014 [18], we know the basic needs of a household consist of eight consumer items, they are food (item-1), clothing (item-2), household appliances and service (item-3), health care and medical services (item-4), transport and communications (item-5), education, cultural and recreation services (item-6), housing (item-7), miscellaneous goods and services (item-8). From formula (2),we can get

$$
\left(\begin{array}{llll}
1-\beta_{1}-\beta_{1} & \cdots & -\beta_{1} \\
-\beta_{2} & 1-\beta_{2} & \cdots & -\beta_{2} \\
\vdots & \vdots & \vdots & \vdots \\
-\beta_{8} & -\beta_{8} & \cdots & 1-\beta_{8}
\end{array}\right) \times\left(\begin{array}{l}
P_{1} r_{1} \\
P_{2} r_{2} \\
\vdots \\
P_{8} r_{8}
\end{array}\right)=\left(\begin{array}{l}
b_{1} \\
b_{2} \\
\vdots \\
b_{8}
\end{array}\right)
$$


Then, we get

$$
\left(\begin{array}{l}
P_{1} r_{1} \\
P_{2} r_{2} \\
\vdots \\
P_{8} r_{8}
\end{array}\right)=\left(\begin{array}{llll}
1-\beta_{1} & -\beta_{1} & \cdots & -\beta_{1} \\
-\beta_{2} & 1-\beta_{2} & \cdots & -\beta_{2} \\
\vdots & \vdots & \vdots & \vdots \\
-\beta_{8} & -\beta_{8} & \cdots & 1-\beta_{8}
\end{array}\right)^{-1} \times\left(\begin{array}{l}
b_{1} \\
b_{2} \\
\vdots \\
b_{8}
\end{array}\right)
$$

Let $Y_{j}$ is the annual disposable income of a household on the income level of $j$, the monthly affordable repayment of the household on the income level of $j$ is

$$
w_{j} m_{j}=\left(Y_{j}-\sum_{i=1}^{8} P_{i} r_{i}\right) \times \frac{1}{12}
$$

$m_{j}$ is the monthly disposable income of the household on the income level of $j, w_{j}$ is the proportion that the household on the income level of $j$ uses on the repayment for house, $n$ is the loan period, $r$ is the annual loan interest rate, $P$ is the house price, and $x$ is the down payment ratio.

Let $\Omega_{1}=\{1,2\}$, where 1,2 respectively represent the new commercial housing and second-hand housing. Let $\Omega_{2}=\{1,2,3,4,5,6\}$, where $1,2,3,4,5,6$ represent the average-income household, low-income household, medium-low-income household, medium-income household, medium-high-income household, and high-income household respectively. According to the formula equal repayment of housing loans, we can get

$$
(1-x) \times P \times\left(1+\frac{r}{12}\right)^{12 n}=w_{j} m_{j} \times \frac{\left(1+\frac{r}{12}\right)^{12 n}-1}{\frac{r}{12}} \quad j \in \Omega_{2}
$$

Housing affordability of the household on the income level of $j$ is

$$
P_{j}=w_{j} m_{j} \times \frac{\left(1+\frac{r}{12}\right)^{12 n}-1}{\frac{r}{12}} \times \frac{1}{(1-x) \times\left(1+\frac{r}{12}\right)^{12 n}} \quad j \in \Omega_{2}
$$

Then we can measure housing affordability of the urban household on the income level of $j$ in Beijing by (8).

We calculate the affordable housing squares of the urban household on the income level of $j$ in Beijing can buy from new commercial real estate market and second-hand real estate market,

$$
S_{i}=\frac{P_{j}}{p_{i}}, i \in \Omega_{1}, j=\Omega_{2}
$$

Here, $S_{i}$ is the affordable housing square of the urban households in Beijing on the income level of $j$ can buy, $p_{i}$ is the house price.

The flow path of how to use ELES model to calculate housing affordability is as follow (Fig. 1). 


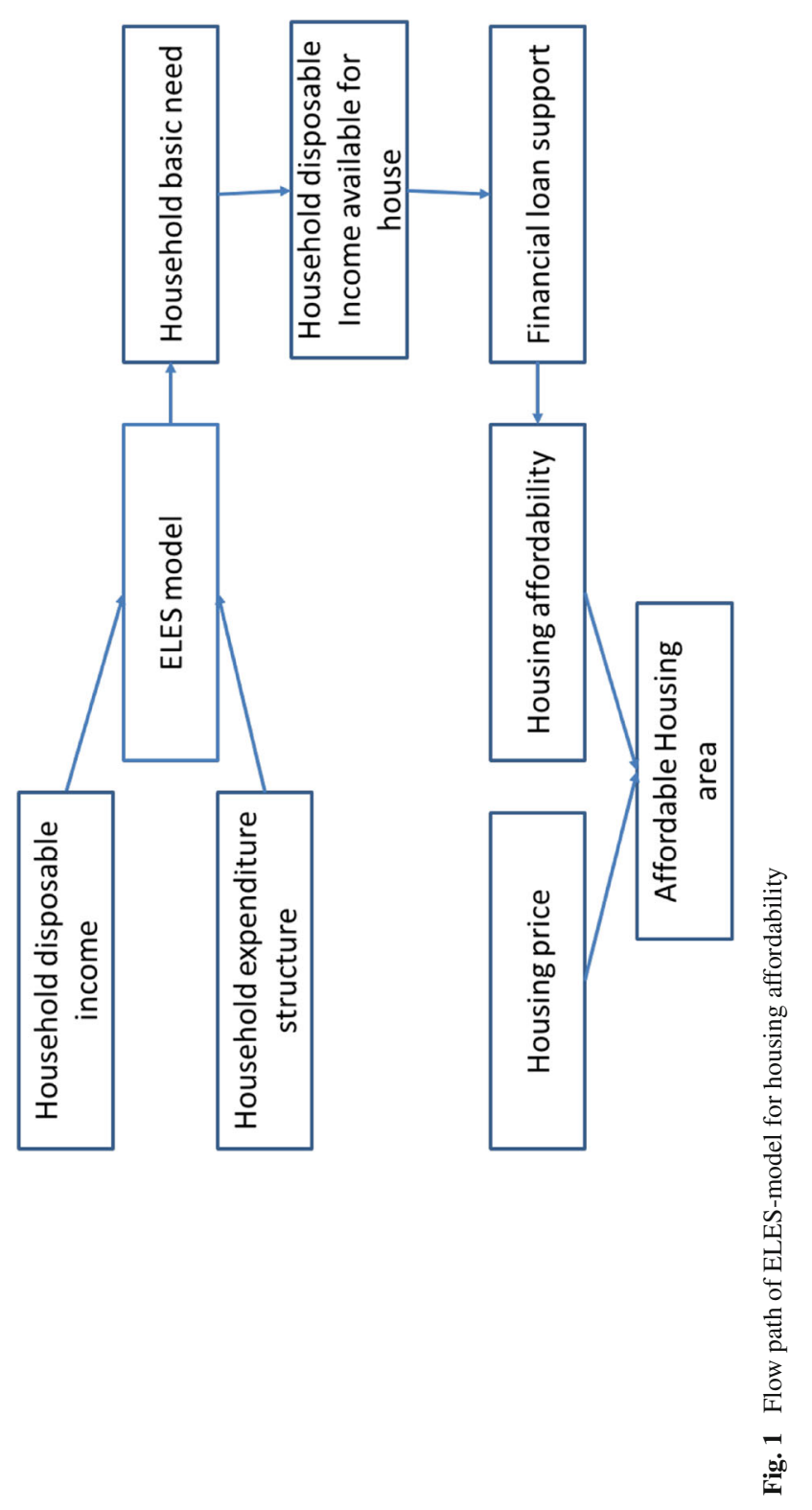




\section{Empirical researches}

By Statistical Information Network of Beijing [19] and Beijing Statistical Yearbook 2005 [20], we can obtain the data about urban households in Beijing, as shown in Tables 1 and 2 .

Running linear regressions, then we can get the estimated values of $b_{i}$ and $\beta_{i}$.

Using the estimated values of $b_{i}$ and $\beta_{i}$ in Table 3, we can calculate the basic life consumer demand of urban residents in Beijing in 2014 and 2004, shown in Table 4.

According to the formula (5), we can measure the monthly affordable money that urban households in Beijing can pay for housing in 2014 and 2004, as shown in Table 5.

From Table 5, we can find that, for the urban households on the low income level in Beijing in 2004, their household disposable incomes were less than the basic consumer expenditure, these household needed the government's support to maintain the expenditure of the basic living needs, and they were unable to purchase houses in 2004. In 2014, for all income levels of urban households in Beijing, the monthly affordable payments for housing are more than 0 , which means that all income levels of urban households in Beijing can cover their basic life consumer expenditure, so they had the remaining income available for purchasing houses. Comparing the monthly affordable payments for housing of the urban households in 2004 and 2014, we can find

Table 1 Consumption expenditure and disposable incomes of urban households in Beijing 2014

\begin{tabular}{lrrrrrrrrr}
\hline Income level & Item-1 & Item-2 & Item-3 & Item-4 & Item-5 & Item-6 & Item-7 & Item-8 & Income \\
\hline Average & 22,271 & 7490 & 5529 & 4804 & 11,370 & 10,759 & 5681 & 4360 & 113,288 \\
Low & 18,543 & 4767 & 3816 & 3405 & 6288 & 6681 & 4626 & 2106 & 63,540 \\
Medium-low & 21,022 & 6174 & 4742 & 4814 & 8770 & 8059 & 4356 & 3141 & 91,385 \\
Medium & 20,288 & 6603 & 4410 & 5022 & 11,188 & 9710 & 4663 & 2985 & 97,752 \\
Medium-high & 23,787 & 7371 & 5601 & 5095 & 10,818 & 12,664 & 5552 & 5113 & 122,545 \\
High & 26,079 & 11,204 & 8292 & 5303 & 17,169 & 14,496 & 8535 & 7417 & 168,537 \\
\hline
\end{tabular}

Unit (Yuan)

Table 2 Consumption expenditure and disposable income of urban households in Beijing 2004

\begin{tabular}{lrllllllll}
\hline Income level & Item-1 & Item-2 & Item-3 & Item-4 & Item-5 & Item-6 & Item-7 & Item-8 & Income \\
\hline Average & 11,384 & 3081 & 2389 & 3430 & 4530 & 6136 & 3090 & 1340 & 45,350 \\
Low & 9174 & 1616 & 1369 & 2138 & 2648 & 4051 & 2047 & 622 & 23,683 \\
Medium-low & 11,188 & 2632 & 1774 & 3361 & 3453 & 5345 & 2301 & 974 & 33,978 \\
Medium & 11,667 & 3090 & 1750 & 3171 & 3490 & 5582 & 2352 & 1132 & 41,311 \\
Medium-high & 12,461 & 3761 & 2711 & 4603 & 4707 & 7157 & 3298 & 1631 & 53,518 \\
High & 13,752 & 4707 & 4630 & 4336 & 8874 & 9298 & 5809 & 2512 & 80,013 \\
\hline
\end{tabular}

Unit (Yuan) 
Table 3 The estimated coefficients of the extended linear expenditure system model

\begin{tabular}{|c|c|c|c|c|c|c|c|c|c|}
\hline Years & $i$ & 1 & 2 & 3 & 4 & 5 & 6 & 7 & 8 \\
\hline \multirow[t]{2}{*}{2014} & $b_{i}$ & $13,903.8$ & 659.1 & 663.0 & 3078.4 & 102.9 & 1734.9 & 1165.4 & -1634.0 \\
\hline & $\beta_{i}$ & 0.074 & 0.060 & 0.043 & 0.015 & 0.099 & 0.079 & 0.040 & 0.053 \\
\hline \multirow[t]{2}{*}{2004} & $b_{i}$ & 8186.8 & 722.7 & -317.2 & 1770.9 & -531.3 & 1980.0 & -60.4 & -194.7 \\
\hline & $\beta_{i}$ & 0.074 & 0.052 & 0.059 & 0.037 & 0.111 & 0.092 & 0.069 & 0.034 \\
\hline
\end{tabular}

Table 4 The basic expenditure of urban residents in Beijing

\begin{tabular}{lllllllllll}
\hline Years & Consumer items & Item-1 & Item-2 & Item-3 & Item-4 & Item-5 & Item-6 & Item-7 & Item-8 & Total \\
\hline 2014 & $\begin{array}{l}\text { Basic expenditure } \\
\text { (Yuan) }\end{array}$ & $16,617.1$ & 2874.4 & 2250.2 & 3635.6 & 3733.4 & 4637.7 & 2641.4 & 317.3 & $36,707.2$ \\
2004 & $\begin{array}{l}\text { Basic expenditure } \\
\text { (Yuan) }\end{array}$ & 9999 & 1996 & 1127 & 2677 & 2187 & 4233 & 1629 & 638 & 24,485 \\
& & & & & & & & & \\
\hline
\end{tabular}

Table 5 The monthly affordable payment of urban households for housing

\begin{tabular}{llllllll}
\hline Years & Income level & Average & Low & Medium-low & Medium & Medium-high & High \\
\hline 2014 & $\begin{array}{c}\text { The monthly } \\
\text { affordable } \\
\text { payment (Yuan) }\end{array}$ & 6382 & 2236 & 4556 & 5087 & 7153 & 10,986 \\
2004 & $\begin{array}{c}\text { The monthly } \\
\text { affordable } \\
\text { payment (Yuan) }\end{array}$ & 1739 & -67 & 791 & 1402 & 2419 & 4627 \\
\hline
\end{tabular}

Table 6 Housing affordability of urban households in Beijing

\begin{tabular}{llllllll}
\hline Years & Income level & Average & Low & Medium-low & Medium & Medium-high & High \\
\hline 2014 & $\begin{array}{c}\text { Housing affordability } \\
\text { (million Yuan) }\end{array}$ & 160 & 56 & 115 & 128 & 180 & 276 \\
2004 & $\begin{array}{c}\text { Housing affordability } \\
\text { (million Yuan) }\end{array}$ & 44 & -2 & 20 & 35 & 61 & 116 \\
\hline
\end{tabular}

that, after ten years of development, the monthly affordable payments for housing of the urban households in Beijing had been significantly improved, in this way we can conclude the capabilities of the urban households in Beijing to pay for housing are enhanced.

Set the annual loan interest rate $\mathrm{r}=5.51 \%$, the down payment ratio is $30 \%, \mathrm{n}$ $=30$ years [20] is the loan period. And according to Eq. (8), we measure housing affordability of the urban households on different income levels in Beijing, the results are shown in Table 6. 
Comparing housing affordability of the urban households on different income levels in Beijing in 2004 and 2014, it shows that, housing affordability of the urban households in Beijing had improved. In 2014, the housing affordability of the urban households in Beijing range from 56 million Yuan to 276 million Yuan.

According to the website of Soufang [21], in 2014 the average price of new commercial housing in eight districts of Beijing was $32,711 \mathrm{Yuan} / \mathrm{m}^{2}$, the average price of Second-hand housing in eight districts of Beijing is 38,454 Yuan $/ \mathrm{m}^{2}$; According to Real Estate Market Conditions of Beijing in 2005 [22], we can know the average price of new commercial houses in Beijing in 2004 was 5642 Yuan $/ \mathrm{m}^{2}$, the average price of Second-hand housing in Beijing in 2004 was 3921 Yuan $/ \mathrm{m}^{2}$. Then we can measure the affordable housing squares that the urban households on different income levels in Beijing can buy via Eq. (9). We refer the affordable housing squares that the urban households on different income levels in Beijing and house prices in 2013 to Li [18]. The results are shown in Table 7.

From Table 7, it shows that, for the low-income urban households in Beijing, the affordable housing squares changed from negative to positive because of the increased household disposable income and the improved housing affordability, the low-income urban households improved their housing conditions, but these families could buy only a little of housing squares. In fact, there are some public policy to support the low-income household's housing and they can apply affordable house to live with a low payment in Beijing. For all income levels of urban households in Beijing, except the low-income level, they cost more money and get less housing squares in 2014 compared with 2004. For medium, medium-high and high income levels, they expend more money and get less housing squares from new commercial housing market; they cost more money and get more housing squares from second-hand housing market in 2014 compared with 2013.

We compare the house prices and the housing affordability of urban residents in Beijing in 2004, 2013, 2014, to find the relations between the growth rates of housing affordability and housing prices. We refer housing affordability and housing prices of 2013 to Li [18]. The results are shown in Table 8.

From Table 8, all income levels of urban households in Beijing, except the lowincome urban households, the growth multiples of the housing affordability are less than the housing price comparing 2004 and 2014, no matter what new commercial housing or second-hand housing. So the affordable housing squares of the urban households of all income levels of urban households in Beijing, except the low-income urban households, are less. Comparing 2013 and 2014, for medium, medium-high and high income levels urban households in Beijing, the growth multiples of the housing affordability are more than the growth multiples of the housing price in second-hand housing market and less than the growth multiples of the housing price in new commercial housing market. So they can afford more housing squares in second-hand housing market and less in new commercial housing. 
Table 7 Affordable housing squares of urban households at different income levels

\begin{tabular}{|c|c|c|c|c|c|c|c|c|}
\hline Years & Income level & Average & Low & Medium-low & Medium & Medium-high & High & $\begin{array}{l}\text { House prices } \\
\text { (Yuan) }\end{array}$ \\
\hline \multirow[t]{2}{*}{2014} & $\begin{array}{l}\text { New housing squares } \\
\left(\mathrm{m}^{2}\right)\end{array}$ & 49.0 & 17.2 & 35.0 & 39.1 & 55.0 & 84.4 & 32,711 \\
\hline & $\begin{array}{l}\text { Second-hand housing } \\
\text { squares }\left(\mathrm{m}^{2}\right)\end{array}$ & 41.7 & 14.6 & 29.8 & 33.2 & 46.8 & 71.8 & 38,454 \\
\hline \multirow[t]{2}{*}{2013} & $\begin{array}{l}\text { New housing squares } \\
\left(\mathrm{m}^{2}\right)\end{array}$ & 51.7 & 14.4 & 33.0 & 39.9 & 56.6 & 85.4 & 28,700 \\
\hline & $\begin{array}{l}\text { Second-hand housing } \\
\text { squares }\left(\mathrm{m}^{2}\right)\end{array}$ & 39.0 & 10.8 & 24.9 & 30.1 & 42.7 & 64.4 & 38,036 \\
\hline \multirow[t]{2}{*}{2004} & $\begin{array}{l}\text { New housing square } \\
\left(\mathrm{m}^{2}\right)\end{array}$ & 77.5 & -3.0 & 35.2 & 62.5 & 107.8 & 206.1 & 5642 \\
\hline & $\begin{array}{l}\text { Second-hand housing } \\
\text { areas }\left(\mathrm{m}^{2}\right)\end{array}$ & 111.4 & -4.3 & 50.7 & 89.9 & 155.1 & 296.6 & 3921 \\
\hline
\end{tabular}

Table 8 The housing prices and the housing affordability of urban residents in Beijing

\begin{tabular}{|c|c|c|c|c|c|c|c|c|}
\hline \multirow[t]{2}{*}{ Years } & \multicolumn{2}{|c|}{ Housing price } & \multicolumn{6}{|c|}{ Housing affordability with different income level } \\
\hline & $\begin{array}{l}\text { New } \\
\text { commercial }\end{array}$ & Second-hand & Average & Low & Medium-low & Medium & Medium-high & High \\
\hline 2014 & 32,711 & 38,454 & 160 & 56 & 115 & 128 & 180 & 276 \\
\hline 2013 & 28,700 & 38,036 & 148 & 41 & 95 & 115 & 162 & 245 \\
\hline 2004 & 5642 & 3921 & 44 & -2 & 20 & 35 & 61 & 116 \\
\hline $\begin{array}{l}\text { The ratio of housing } \\
\text { price in } 2014 \text { to that } \\
\text { in } 2004\end{array}$ & 4.798 & 8.807 & 2.670 & & 4.759 & 2.628 & 1.957 & 1.374 \\
\hline $\begin{array}{l}\text { The ratio of housing } \\
\text { price in } 2014 \text { to that } \\
\text { in } 2013\end{array}$ & 0.140 & 0.011 & 0.081 & 0.362 & 0.208 & 0.116 & 0.106 & 0.127 \\
\hline
\end{tabular}

According to the Ministry of Construction [23], the commercial residential squares in the real estate market were mainly $90-140 \mathrm{~m}^{2}$, which is more than the affordable housing squares most urban households could purchase, made the problem of purchasing houses for urban households in Beijing even worse.

\section{Conclusions}

In this paper, we measure the housing affordability and the affordable housing squares of the urban households on different income levels in Beijing in 2014 and 2004 based on the extended linear expenditure system model. After ten years of development, the household disposable incomes of urban households in Beijing increase. They can afford the expenditure of basic needs and have more remaining disposable incomes to purchase houses. The housing affordability of urban households on different income levels in Beijing had enhanced. The increasing disposable incomes enhanced the hous- 
ing affordability of urban households in Beijing, in this respect, all income levels of urban households in Beijing have improved their housing conditions. But from the view of the affordable housing squares, their housing conditions depend on the housing price deeply. If the growth of house price is faster than the growth of housing affordability, the affordable housing squares will decrease, and the housing condition of urban households in Beijing will be worse.

With the development of economy and with the support of financial housing loans, suppose that the annual interest rate of housing loan and the loan period unchanged, the more disposable income it is, the stronger housing affordability it is. To solve the problem of purchasing house for urban residents, the government would increase the disposable incomes of urban residents step by step. In addition, the government would control the reasonable growth of house price. What's more, real estate business providing housing should take housing affordability and the affordable housing squares of urban residents into account.

In this study, we study housing affordability from the micro level and consider factors such like the structure of expenditure, the household disposable income and the commercial housing loans. Comparing to dynamic methods, ELES-model is a static method. In future study, we should consider some dynamic methods and macroeconomic factors that affect housing affordability.

Acknowledgments This research is partially supported by the grants (71401188 and 70921061) from the National NSFC, the 121 funding and Program in CUFE. Part of this paper was presented at the third International Conference on Information Technology and Quantitative Management (ITQM 2015).

\section{References}

1. Hulchanski JD (1995) The concept of housing affordability: six contemporary uses of the housing expenditure-to-income ratio. Housing Studies 10(4):471-491

2. Freeman A, Chaplin R, Whitehead CME (1997) Rental affordability: a review of international literature. University of Cambridge, Department of Land Economy

3. Stone ME (2006) What is housing affordability? The case for the residual income approach. Housing policy debate $17(1): 151-184$

4. Li A, Shi Y, Zhu M (2008) Study on dynamic model and demonstration for housing purchasing power measuring. China Manag Sci 6:157-163. http://cpfd.cnki.com.cn/Article/ CPFDTOTAL-ZHYJ200810001033.htm

5. Li A, Liu J (2009) Computation and comparative study of PIR and HAI with demonstration analysis in Beijing. IEEE Int Joint Conf Comput Sci Optim 1:1012-1015

6. Wang Y, Zhang Y (2013) Establishment of the function of housing price-to-income ratio and preliminary application_ _ taking Shanghai city as an example. East China Econ Manag 8:001

7. Zhang Q (2012) Comparing the ratio of housing price to income with the housing affordability index. China Land Sci 1:008

8. Ji K, Kim J, Kim J (2006) Housing affordability index in Korea. Hous Urban Aff Rev 38:37-53

9. Abeysinghe T, Gu J (2011) Lifetime income and housing affordability in Singapore. Urban Stud 48(9):1875-1891

10. Lluch C (1973) The extended linear expenditure system. Eur Econ Rev 4(1):21-32

11. Stone R (1954) Linear expenditure systems and demand analysis: an application to the pattern of British demand. Econ J 64:511-527

12. Ali MS (1985) Household consumption and saving behaviour in Pakistan: an application of the extended linear expenditure system. Pak Dev Rev 24(1):23-37

13. Su F, Xu ZM, Shang HY (2009) Rural resident household food consumption patterns in the Ganzhou district of Zhangye city: an analysis based on ELES model. Sci Cold Arid Reg 1(2):0177-0184 
14. Li W, Fan L, Hongpeng G (2011) Comparative analysis for consumption structures of rural residents in Jilin Province based on ELES model. In: IEEE conference on control and decision conference (CCDC), pp 3350-3355

15. Bin X, Renjing X (2012) An empirical analysis on the consumption structure of town residents, Jiangxi Province-based on the extended linear expenditure system model (ELES). Phys Proc 24:660-666

16. Li T (2011) Research on consumption structure of rural residents in Gansu province based on ELSE model. Asian Agric Res 03(9)

17. Li A, SU J (2010) Research on affordable public housing price based on ELES. In: The proceeding of the twelfth management science of China

18. Li A, Mo Q (2015) ELES-model based housing affordability comparative research of urban households in Beijing between 2004 and 2013. Proc Comput Sci 55:1079-1086

19. http://www.bjstats.gov.cn

20. http://www.chinamoney.com.cn/fe/Channel/2000437?_tp_t10762750655401=3\&label=1

21. http://fangjia.fang.com/

22. http://www.bjjs.gov.cn/publish/portal0/tab662/info1546.htm

23. http://www.bjjs.gov.cn/publish/portal0/tab662/info87098.htm

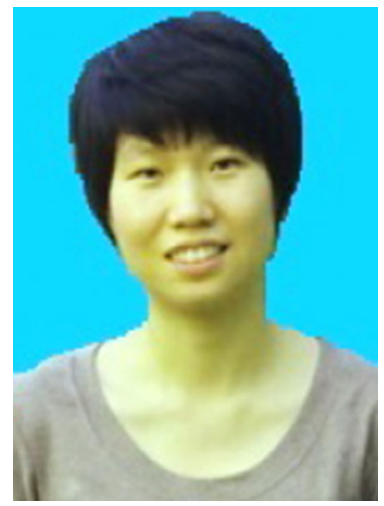

Aihua Li received the bachelor degree in Applied Mathematics from Northeast University (NEU) in 2001, and received the master degree in Operational Research \& Control theory from NEU in 2004. She then received the PHD degree from Graduate School of Chinese Academy of Sciences (GUCAS) in Management Science and Engineering in 2007. Now she is an association professor in Central University of Finance and Economics (CUFE). She has published more than 30 papers in national and international journals, and conference proceedings. Her research interest includes data mining theory and application, decision science, and operational research.

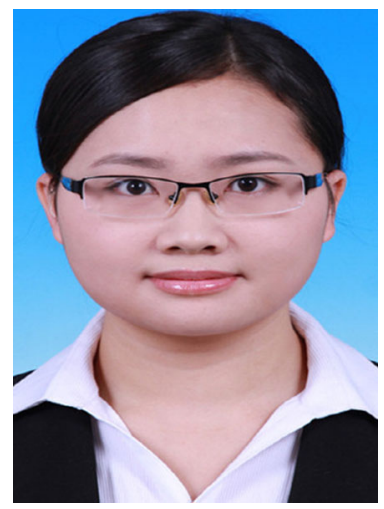

Qingqing Mo was born in Guangxi province, China in 1991. She graduated from School of management science and engineering, Central University of Finance and Economics (CUFE), in 2014. Now she is a graduate student of School of management science and engineering in Central University of Finance and Economics (CUFE), major in management science and engineering. Her research interests include data mining and real estate. 

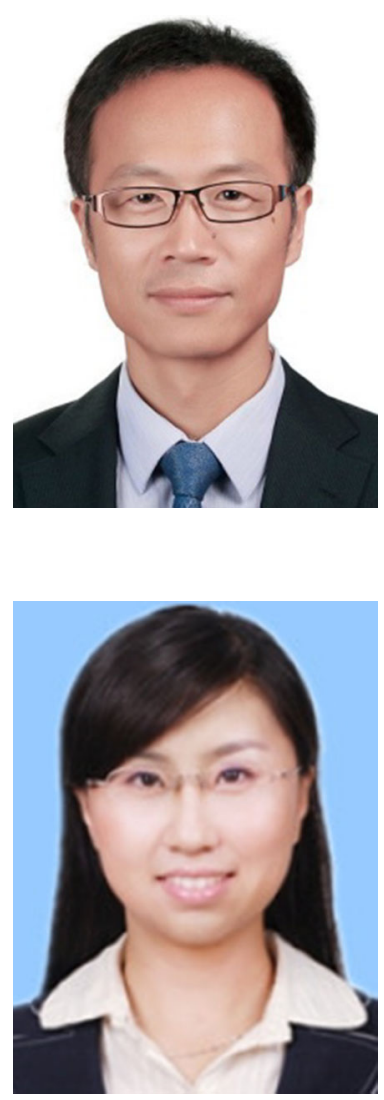

Wenbin Li received the $\mathrm{PhD}$ degree in economics from Nankai University in 2003. Now he is the professor in the department of real estate management, school of management science and engineering, Central University of Finance and Economics. He has published more than 30 papers in the journals and conference. And he is the author for the book named International Real Estate Investment: Benefits, Risks and System. His research interest includes real estate economics, urban economics and real estate finance.

Yuejin Zhang received the bachelor degree in Information Management and Information Systems from Central University of Finance and Economics in 2005, and received the PHD degree in Management Science and Engineering from Graduate School of Chinese Academy of Sciences in 2010. Now she is an assistant professor in Central University of Finance and Economics. She has published more than 20 papers in national and international journals, and conference proceedings. Her research interest includes data mining theory and application, knowledge management, and internet finance. 